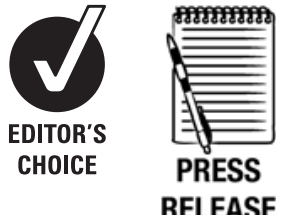

RELEASE

ORIGINAL ARTICLE

\title{
Cardiovascular disease mortality among British asbestos workers (1971-2005)
}

\author{
Anne-Helen Harding, ${ }^{1}$ Andrew Darnton, ${ }^{2}$ John Osman ${ }^{2}$
}

${ }^{1}$ Mathematical Sciences Unit, Health and Safety Laboratory, Buxton, Derbyshire, UK ${ }^{2}$ Health and Safety Executive, Bootle, Merseyside, UK

\section{Correspondence to} Dr Anne-Helen Harding, Mathematical Sciences Unit, Health and Safety Laboratory, Harpur Hill, Buxton, Derbyshire SK17 9JN, UK: anne-helen.harding@hsl.gov.uk

Accepted 6 February 2012 Published Online First

2 April 2012

\begin{abstract}
Objectives Asbestos is an inflammatory agent, and there is evidence that inflammatory processes are involved in the development of cardiovascular disease. Whether asbestos is a risk factor for cardiovascular disease has not been established. The objective of this study was to investigate cardiovascular disease mortality in a large cohort of workers occupationally exposed to asbestos.

Methods Cardiovascular disease mortality in a cohort of 98912 asbestos workers, with median follow-up of 19 years, was analysed. Unadjusted and smokingadjusted standardised mortality ratios (SMRs) were calculated. The association between indicators of asbestos exposure and mortality was analysed with Poisson regression models, for deaths occurring during the period 1971-2005.
\end{abstract}

Results Altogether 15557 deaths from all causes, 1053 deaths from cerebrovascular disease and 4185 deaths from ischaemic heart disease (IHD) occurred during follow-up. There was statistically significant excess mortality from cerebrovascular disease (SMR: men 1.63, women 2.04) and IHD (SMR: men 1.39, women 1.89). Job and birth cohort were associated with the risk of cerebrovascular and IHD mortality in the Poisson regression model including sex, age, smoking status, job, cohort and duration of exposure. For IHD only, duration of exposure was also statistically significant in this model.

Conclusions Cerebrovascular and IHD mortality was significantly higher among these asbestos workers than in the general population and within the cohort mortality was associated with indicators of asbestos exposure. These findings provide some evidence that occupational exposure to asbestos was associated with cardiovascular disease mortality in this group of workers.

\section{INTRODUCTION}

Inflammation plays a central role in the pathogenesis of cardiovascular disease. ${ }^{1}$ A substantial body of evidence exists, which demonstrates that long-term exposure to airborne particulate matter is associated with cardiovascular diseases and atherosclerosis. ${ }^{2} 3$ Inflammation, oxidative stress and the promotion of atherosclerosis have been observed in animal models exposed to airborne particulate matter, ${ }^{45}$ and cohort data exist linking airway inflammation with the risk of ischaemic heart disease (IHD). ${ }^{6}$ Asbestos also has a strong inflammatory effect and promotes atherogenesis in animal models. ${ }^{7-9}$ An increased risk of cardiovascular disease mortality associated with exposure to asbestos, as suggested in some exposed cohorts, ${ }^{10-13}$ could thus be a result of similar underlying mechanisms as for particulates even

\section{What this paper adds}

- In this large cohort of workers occupationally exposed to asbestos, there was an excess risk of cardiovascular disease mortality after adjusting for smoking.

- The risk of cerebrovascular disease, and ischaemic heart disease mortality in particular, was associated with indicators of exposure to asbestos.

though the physical characteristics of asbestos fibres and particulates are different.

The primary focus of studies of asbestos-exposed workers tends to be on the major asbestos-related diseases, namely mesothelioma, lung cancer and asbestosis, and the majority of these studies have no information on cigarette smoking. Consequently detailed analysis of cardiovascular disease outcomes with adjustment for smoking have not typically been undertaken, although one study of Swedish shipyard workers exposed to asbestos has reported an age- and smoking-adjusted RR of IHD (3.1; 95\% CI 1.5 to 6.4). ${ }^{14}$ Previous analysis of the British asbestos workers cohort found statistically significantly raised standardised mortality ratios (SMRs) for cerebrovascular disease (CD) and $\mathrm{IHD}^{15}$, and a separate analysis of the removal workers in the cohort-indicated significant excess mortality from circulatory diseases. ${ }^{1617}$ The objective of the current study was to undertake a detailed analysis of cerebrovascular and IHD mortality in relation to information on smoking behaviours and indicators of asbestos exposure among British asbestos workers.

\section{METHODS}

In 1971, the Asbestos Workers Survey was established in order to monitor the long-term health of workers covered by regulations to control occupational exposure to asbestos. Details of the survey have been published previously. ${ }^{15}$ In brief, workers taking part in voluntary medical surveillance for the early detection of asbestos-related disease under the 1969 Asbestos Regulations were included in the survey, as well as workers undergoing regular statutory medical examinations as required by the 1983 Asbestos Licensing Regulations and subsequent regulations. At the time of the medical, workers were invited to participate in the survey and to complete the survey questionnaire. The questionnaire requested information on duration of occupational exposure to asbestos, current job type and 
smoking history. Information on job type and smoking history were updated for workers returning for further medicals. Workers, who agreed to take part in the survey, were flagged for death registrations with the National Health Service Central Register; 98\% of workers were successfully traced. The British Medical Association Research Ethics Committee gave approval for the original survey.

\section{Causes of death}

The end points for the study were two forms of cardiovascular disease: CD (International Classification of Diseases (ICD) codes 430-438 for ICD-9 and codes I60-I69 for ICD-10) and IHD (ICD codes 410-414 (ICD-9) and codes I20-I25 (ICD10)) mortality, identified through the underlying cause of death. Deaths occurring to the end of 2005 were included in the study.

\section{Statistical methods}

SMRs were calculated by sex-specific 5 -year age and calendar time periods, using mortality rates for Great Britain (GB). The population attributable fraction due to smoking was calculated for the general population using the formula for multicategory exposures, ${ }^{18}$ published data on risks of mortality among current and former smokers relative to never-smokers ${ }^{19} 20$ and the average prevalence of smoking in the general population of Great Britain over the period. ${ }^{21}$ Smoking-adjusted SMRs could then be calculated using the formula given in $\mathrm{Yu}$ and $\mathrm{Tse}^{22}$ Proportional mortality ratios (PMRs) were calculated to provide comparisons of mortality by job type within the cohort; PMRs rather than SMRs were used to show the relative importance of different causes of death in this cohort. Poisson regression was used to investigate whether potential indicators of asbestos exposure were related to cardiovascular disease mortality. Person-years at risk were calculated from the date of the first medical examination to the end of the study period, the date of death or the date of emigration, whichever was earliest. Four job types were used in the analysis: manufacturing, removal, 'other exposed' and insulation work. For the analysis, individuals were allocated to the job type they had spent most time in. Smoking status (current, former and never-smoker), age attained and duration of exposure were entered as time-varying covariates in the Poisson regression models. Relative risks of mortality were calculated within smoking categories, using predicted mortality rates from the Poisson regression models. For example, the mortality risk for a non-smoker aged over 70 years relative to that of a non-smoker aged $<40$ years and the mortality risk for a current smoker aged over 70 years relative to that of a current smoker aged $<40$ years were calculated. The models were checked for goodness of fit using Pearson's $\chi^{2}$ statistic.

\section{RESULTS}

During the period 1971-2005, 99680 men and women agreed to participate in the survey. After exclusions for incomplete data or unsuccessful flagging, 98912 individuals were included in the analysis. There were 15557 deaths from all causes, 1053 deaths from CD and 4185 deaths from IHD during the follow-up period (table 1). Over $55 \%$ of men and women completed only one survey questionnaire, and the median follow-up time was 19.3 years. The mean age overall at the first medical exam was 35 years; the majority of men were in the asbestos removal industry, while the majority of women were in the manufacturing industry. The proportional mortality ratios for lung cancer, asbestosis and mesothelioma differed substantially between the job categories: insulation workers (PMR lung cancer=131; PMR asbestosis=10814; PMR mesothelioma=1828) and removal workers (PMR lung cancer=143; PMR asbestosis=4944; PMR mesothelioma $=1398$ ) had the highest PMRs, while 'other exposed' workers (PMR lung cancer=103; PMR asbestosis=2472; PMR mesothelioma $=709$ ) and manufacturing workers (PMR lung cancer $=109 ;$ PMR asbestosis=1676; PMR mesothelioma $=591$ ) generally had the lowest PMRs. Over $58 \%$ of men and $52 \%$ of women were current smokers at the first medical examination and a slightly smaller per cent (55\% and $49 \%$, respectively) were current smokers at their last recorded medical (table 1). Attributable fractions for smoking were $16 \%$ and $20 \%$ for CD and $23 \%$ and $42 \%$ for IHD for men and women, respectively. The crude death rates for CD were 57 per 100000 and 94 per 100000 and for IHD were 238 per 100000 and 181 per 100000 for men and women, respectively.

SMRs and smoking-adjusted SMRs were calculated to compare mortality among the asbestos workers with those in the GB population (table 2). The SMR for all causes of death was 1.42 (95\% CI 1.39 to 1.44). Overall, in unadjusted calculations, there were statistically significant excesses in cerebrovascular and IHD deaths in both men (SMR CD=1.63, 95\% CI 1.52 to 1.73; SMR IHD $=1.39,95 \%$ CI 1.35 to 1.43 ) and women (SMR $\mathrm{CD}=2.04,95 \%$ CI 1.64 to 2.51 ; SMR IHD $=1.89 ; 95 \%$ CI 1.62 to 2.19). For never-smokers, the SMR for IHD was less than one among men but not so among women. The SMR for CD was elevated for female never-smokers, even though reference rates included smokers. The majority of the other SMRs were statistically significantly elevated.

Adjusting for smoking reduced the overall SMRs for both CD and IHD disease-as expected given the high rates of smoking in this cohort-and reduced the SMRs among smokers while increasing those for non-smokers. Nevertheless, all smokingadjusted SMRs remained statistically significantly greater than 1, except for IHD among male never-smokers and CD and IHD among female former smokers which were not statistically significantly raised.

The Poisson regression analysis showed that, adjusted for age and smoking status, women had a similar risk of CD mortality as men ( $R R=1.04,95 \%$ CI 0.84 to 1.30$)$ but that women had a significantly lower risk of IHD than men $(\mathrm{RR}=0.55,95 \% \mathrm{CI}$ 0.47 to 0.64 ) (table 3 ). Adjusted for sex and smoking status, risk of mortality for both diseases increased rapidly with age:

Table 1 Characteristics of the British asbestos workers (1971-2005)

\begin{tabular}{lll}
\hline & Men & Women \\
\hline Number & $94403(95.4 \%)$ & $4509(4.6 \%)$ \\
Person-years at risk & 1677102 & 103392 \\
Median years at risk & 19.1 & 25.9 \\
Mean age at first exam (SD) & $35.4(12.0)$ & $36.1(13.1)$ \\
Main job* & & \\
$\quad$ Manufacturing & $25683(28 \%)$ & $2895(64 \%)$ \\
$\quad$ Removal & $50614(54 \%)$ & $610(14 \%)$ \\
$\quad$ 'Other' exposed & $12037(13 \%)$ & $822(18 \%)$ \\
$\quad$ Insulation & $5039(5 \%)$ & $173(4 \%)$ \\
Current smokers at first exam $\dagger$ & $53756(58 \%)$ & $2251(52 \%)$ \\
Current smokers at last exam† & $50455(55 \%)$ & $2120(49 \%)$ \\
Cerebrovascular disease (n) & 956 & 97 \\
$\quad$ Crude incidence rate & 57 per 100000 & 94 per 100000 \\
Ischaemic heart disease (n) & 3998 & 187 \\
$\quad$ Crude incidence rate & 238 per 100000 & 181 per 100000 \\
\hline
\end{tabular}

*Excludes 3470 with missing main job information.

†Excludes 3212 missing smoking information at the first medical exam and 2866 at the worker's last medical examination. 
Table 2 Standardised mortality ratios for cerebrovascular and ischaemic heart disease among British asbestos workers (1971-2005)

\begin{tabular}{|c|c|c|c|}
\hline \multirow[b]{2}{*}{ Smoking status } & \multirow{2}{*}{$\begin{array}{l}\text { Number of } \\
\text { deaths }\end{array}$} & \multicolumn{2}{|c|}{ Standardised mortality ratio } \\
\hline & & Unadjusted & Smoking adjusted \\
\hline \multicolumn{4}{|c|}{ Cerebrovascular disease } \\
\hline \multicolumn{4}{|l|}{ Men } \\
\hline Overall & 933 & $1.63(1.52$ to 1.73$)$ & 1.51 (1.42 to 1.61$)$ \\
\hline Current & 580 & 2.03 (1.87 to 2.20$)$ & 1.61 (1.48 to 1.75$)$ \\
\hline Former & 245 & 1.25 (1.10 to 1.42$)$ & 1.36 (1.20 to 1.55$)$ \\
\hline Never & 108 & 1.18 (0.96 to 1.42$)$ & 1.41 (1.16 to 1.70$)$ \\
\hline \multicolumn{4}{|l|}{ Women } \\
\hline Overall & 90 & 2.04 (1.64 to 2.51 ) & 1.86 (1.49 to 2.28$)$ \\
\hline Current & 51 & 2.49 (1.85 to 3.27$)$ & 1.80 (1.34 to 2.37$)$ \\
\hline Former & 10 & 1.31 (0.63 to 2.42 ) & 1.27 (0.61 to 2.23 ) \\
\hline Never & 29 & 1.82 (1.22 to 2.62$)$ & 2.38 (1.59 to 3.41$)$ \\
\hline \multicolumn{4}{|c|}{ Ischaemic heart disease } \\
\hline \multicolumn{4}{|l|}{ Men } \\
\hline Overall & 3870 & 1.39 (1.35 to 1.43$)$ & 1.28 (1.24 to 1.32$)$ \\
\hline Current & 2463 & 1.76 (1.69 to 1.83$)$ & 1.40 (1.35 to 1.46$)$ \\
\hline Former & 1035 & 1.10 (1.03 to 1.16$)$ & 1.15 (1.08 to 1.22$)$ \\
\hline Never & 372 & 0.84 (0.76 to 0.93 ) & 1.04 (0.94 to 1.15$)$ \\
\hline \multicolumn{4}{|l|}{ Women } \\
\hline Overall & 175 & 1.89 (1.62 to 2.19$)$ & 1.61 (1.38 to 1.87$)$ \\
\hline Current & 111 & 2.56 (2.11 to 3.09 ) & 1.61 (1.32 to 1.94$)$ \\
\hline Former & 32 & 1.95 (1.33 to 2.75$)$ & 1.46 (1.00 to 2.06$)$ \\
\hline Never & 32 & 0.97 (0.67 to 1.37 ) & 1.80 (1.23 to 2.55$)$ \\
\hline
\end{tabular}

Data are observed deaths and SMRs, with $95 \% \mathrm{Cl}$ for the SMRs in parentheses. Note that there are missing values in the smoking status data.

compared with workers aged $<40$ years, those aged 70 years or more had relative risks of 198 (95\% CI 125 to 313) for CD and 256 (95\% CI 186 to 354) for IHD. Relative to current smokers, adjusted for age and sex, the risk of mortality from both diseases was substantially lower for former smokers ( $\mathrm{RR} C D=0.61,95 \%$ CI 0.53 to 0.71 ; RR IHD $=0.66,95 \%$ CI 0.61 to 0.70 ) and neversmokers (RR CD $=0.59,95 \%$ CI 0.49 to 0.71 ; RR IHD $=0.44,95 \%$ CI 0.40 to 0.49 ).

Table 4 shows the associations between mortality and indicators of asbestos exposure in Poisson regression models adjusted for age, sex and smoking status. Associations were similar for the two diseases, but they tended to be stronger for IHD mortality. Compared with manufacturing workers, removal workers had significantly lower risk of mortality from both diseases ( $\mathrm{RR} C D=0.74,95 \%$ CI 0.60 to 0.90 ; RR IHD $=0.72,95 \%$ CI 0.65 to 0.79), whereas 'other exposed' workers had a lower risk of mortality from IHD only (RR IHD $=0.86,95 \%$ CI 0.79 to 0.94). However, the risks of $\mathrm{CD}$ and IHD mortality were similar for manufacturing and insulation workers. Mortality was inversely associated with year of birth and for IHD, there was a small increase in mortality with increasing occupational exposure to asbestos.

There was a statistically significant interaction between age and smoking status on IHD mortality $(p<0.001)$ in the analysis adjusted for sex, job, year of birth and duration of exposure. Figure 1 shows IHD mortality rates by age and smoking category. Mortality increased with age in all smoking categories but more rapidly for never-smokers: for current smokers, the RR of IHD in those aged $70+$ years compared with those aged $<40$ years was 37 , whereas in never-smokers, it was 143 . There was also a significant interaction $(\mathrm{p}=0.004)$ between duration of exposure and smoking status in the analysis adjusted for sex, job, smoking status and year of birth, which implied that the positive association between increasing IHD mortality and increasing duration of asbestos exposure was restricted to never-
Table 3 Poisson regression analysis of cerebrovascular disease and ischaemic heart disease mortality in British asbestos workers (1971-2005)

\begin{tabular}{|c|c|c|}
\hline \multicolumn{2}{|c|}{ Cerebrovascular disease } & \multirow[t]{2}{*}{ Ischaemic heart disease } \\
\hline \multicolumn{2}{|c|}{ Sex, adjusted for age and smoking } & \\
\hline & Likelihood ratio test, $\mathrm{p}=0.718$ & Likelihood ratio test, $\mathrm{p} \leq 0.000$ \\
\hline Men & 1.00 & 1.00 \\
\hline Women & $1.04(0.84$ to 1.30$)$ & $0.55(0.47$ to 0.64$)$ \\
\hline \multicolumn{3}{|c|}{ Age attained (years), adjusted for sex and smoking } \\
\hline & Likelihood ratio test, $\mathrm{p} \leq 0.001$ & Likelihood ratio test, $\mathrm{p} \leq 0.001$ \\
\hline$<40$ & 1.00 & 1.00 \\
\hline $40-49$ & $3.98(2.36$ to 6.74$)$ & $10.7(7.61$ to 15.0$)$ \\
\hline $50-59$ & $11.0(6.78$ to 19.7$)$ & $39.1(28.2$ to 54.1$)$ \\
\hline $60-69$ & $40.3(25.3$ to 64.2$)$ & 105 (76.0 to 145$)$ \\
\hline $70+$ & 198 (125 to 313$)$ & 256 (186 to 354$)$ \\
\hline \multicolumn{3}{|c|}{ Smoking status, adjusted for sex and age } \\
\hline & Likelihood ratio test, $\mathrm{p} \leq 0.001$ & Likelihood ratio test, $\mathrm{p} \leq 0.001$ \\
\hline Current & 1.00 & 1.00 \\
\hline Former & 0.61 (0.53 to 0.71$)$ & $0.66(0.61$ to 0.70$)$ \\
\hline Never & $0.59(0.49$ to 0.71$)$ & $0.44(0.40$ to 0.49$)$ \\
\hline
\end{tabular}

Data are relative risks of mortality with $95 \%$ Cls in parentheses. Likelihood ratio test $p$ values show the overall effect of each variable in the model.

and former smokers (figure 2). The risk of IHD mortality for current smokers occupationally exposed to asbestos for 40 or more years was only $6 \%$ higher than for current smokers exposed to asbestos for $<10$ years. However, the risk of IHD mortality in former and never-smokers was, respectively, $54 \%$ and $75 \%$ higher in those exposed to asbestos for 40 or more years compared with former and never-smokers exposed to asbestos for $<10$ years. These interactions were not significant in the models of CD mortality.

\section{DISCUSSION}

There was evidence of increased cerebrovascular and IHD mortality in this large prospective study of asbestos workers with a median follow-up time of 19.3 years. Unadjusted and smoking-

Table 4 Poisson regression analysis* of cerebrovascular disease and ischaemic heart disease mortality in British asbestos workers (1971-2005)

\begin{tabular}{lll}
\hline & $\begin{array}{l}\text { Cerebrovascular } \\
\text { disease }\end{array}$ & $\begin{array}{l}\text { Ischaemic heart } \\
\text { disease }\end{array}$ \\
\hline $\begin{array}{l}\text { Main job } \\
\text { Manufacturing }\end{array}$ & $\mathrm{p}=0.016$ & $\mathrm{p} \leq 0.000$ \\
$\quad 1.00$ & 1.00 \\
Removal & $0.74(0.60$ to 0.90$)$ & $0.72(0.65$ to 0.79$)$ \\
'Other exposed' & $0.88(0.74$ to 1.04$)$ & $0.86(0.79$ to 0.94$)$ \\
$\quad$ Insulation & $0.87(0.69$ to 1.10$)$ & $0.94(0.84$ to 1.05$)$ \\
Year of birth & $\mathrm{p} \leq 0.001$ & $\mathrm{p} \leq 0.001$ \\
$<1930$ & 1.00 & 1.00 \\
$1930-1939$ & $0.63(0.52$ to 0.75$)$ & $0.59(0.54$ to 0.64$)$ \\
$1940-1949$ & $0.35(0.25$ to 0.49$)$ & $0.37(0.32$ to 0.42$)$ \\
$1950+$ & $0.27(0.16$ to 0.44$)$ & $0.19(0.15$ to 0.24$)$ \\
Duration of exposure (years), $\mathrm{p}=0.190$ & $\mathrm{p}=0.001$ & $\mathrm{p}=0.011$ \\
$<10$ & 1.00 & 1.00 \\
$10-19$ & $1.20(0.93$ to 1.56$)$ & $1.16(1.03$ to 1.30$)$ \\
$20-29$ & $1.05(0.80$ to 1.37$)$ & $1.10(0.98$ to 1.24$)$ \\
$30-39$ & $1.04(0.79$ to 1.38$)$ & $1.15(1.02$ to 1.30$)$ \\
$40+$ & $1.22(0.93$ to 1.62$)$ & $1.25(1.10$ to 1.42$)$ \\
\hline
\end{tabular}

Data are relative risks of mortality with $95 \%$ Cls in parentheses.

* For each disease, the data represent a single model including job, year of birth, duration of exposure, sex, age attained and smoking status. Likelihood ratio test $\mathrm{p}$ values show the overall effect of each variable in the model. 


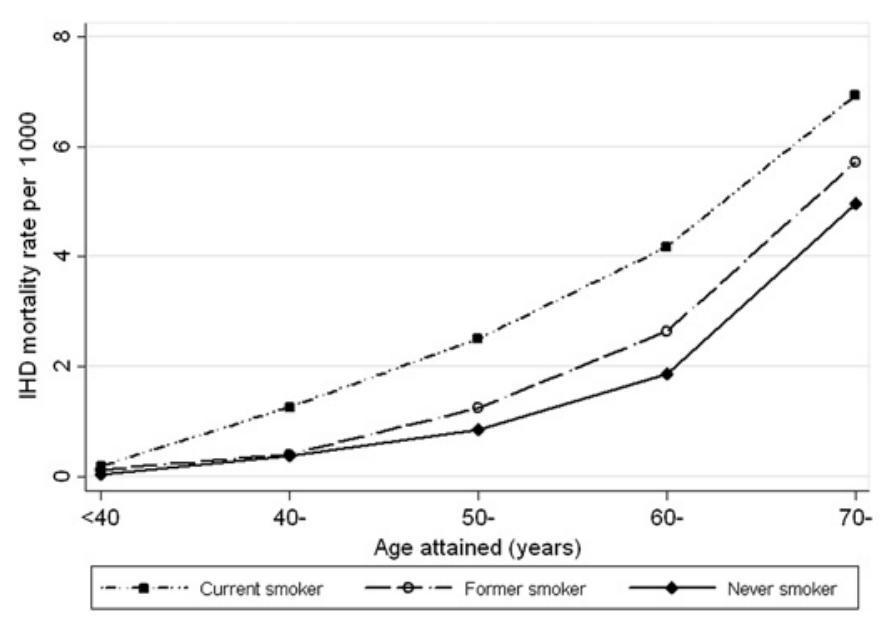

Figure 1 Ischaemic heart disease mortality by smoking status and age attained, adjusted for sex, job, birth year, and duration of exposure to asbestos.

adjusted SMRs, comparing mortality among the asbestos workers with mortality in the GB population, showed a statistically significant excess of deaths among men and women for both cerebrovascular and IHD, both overall and, with a few exceptions, within each smoking status category. The SMRs for all causes and cardiovascular diseases were relatively high for an occupational cohort, but this has also been reported in a number of other asbestos-exposed cohorts. ${ }^{12}{ }^{13}$ Higher mortality rates after adjusting for smoking may be attributable to exposure to asbestos, but they may also be at least partly attributable to occupational class. Compared with non-manual workers, manual workers have increased coronary heart disease incidence. ${ }^{23}$ Depending on socio-cultural context, different components of job strain, for example job control and skill dependency, and in some cohorts also lifestyle factors, may account for much of the difference in risk between occupational classes. ${ }^{23}$

There was also some evidence that the risk of mortality was positively associated with indicators of occupational exposure to asbestos; this was stronger for IHD. In Poisson regression analysis, the risks of CD and IHD were associated with job type and year of birth, and for IHD only, with duration of occupational exposure to asbestos. The evidence from studies of the effect of ambient air pollution is also stronger for IHD than for CD. ${ }^{24}$

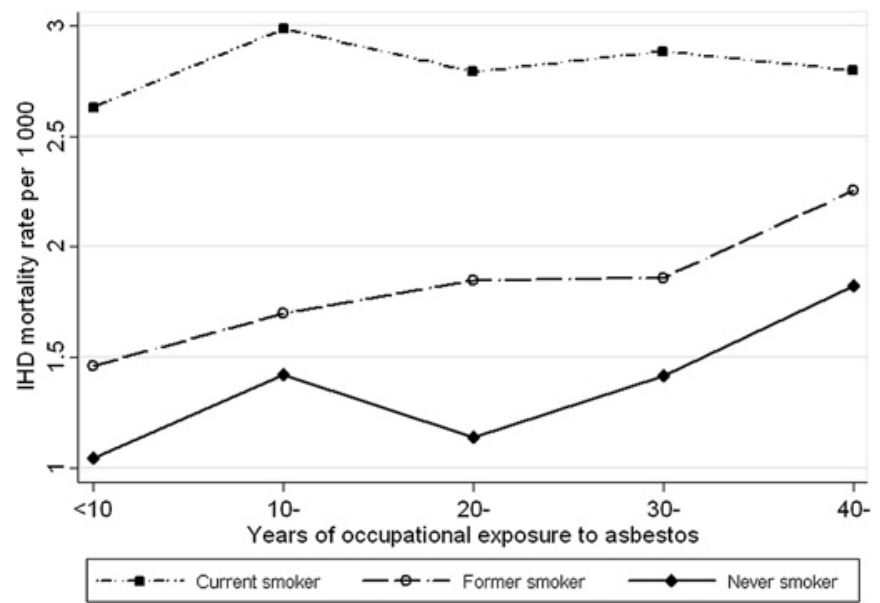

Figure 2 Ischaemic heart disease mortality by smoking status and duration of exposure to asbestos, adjusted for age, sex, job, and birth year.
Mortality was highest among current smokers. Our observation of a more rapid increase in IHD mortality with age among never-smokers than among current and former smokers, which corresponds to a decline with age in the RR for smokers compared with non-smokers, has been observed in other studies. ${ }^{25}$ This is likely to be due to the fact that mortality from IHD, a multi-factorial condition, is generally a major cause of mortality among older age groups. ${ }^{25}$ The interaction between duration of occupational exposure to asbestos and smoking status implies that the mortality rate was positively associated with duration of exposure among never and former smokers, but there was a negligible increase in risk with increasing duration of exposure among current smokers. If true, this suggests that the effect of occupational exposure to asbestos was greater on neverand former smokers than on current smokers and would suggest that the excess of IHD seen among smokers in this cohort after adjusting for smoking was largely a consequence of other factors. However, smoking cigarettes is associated with chronic, systemic inflammation and vascular inflammation, ${ }^{26}$ and thus, the effect of smoking may have masked any effect of asbestos on cardiovascular risk among current smokers within this cohort.

The main limitation with this study was the lack of information on individual exposure to asbestos, so that proxy measures of exposure had to be used. The effect of birth cohort represented overall working conditions, which tended to be dustier and less well controlled in earlier times. However, the cohort effect, which highlighted the lower risk of cardiovascular disease mortality in the later birth cohorts, may also reflect the general fall in cardiovascular disease mortality in the British population during the study period. Duration of exposure was derived assuming that an individual was exposed from the date they reported being first occupationally exposed until the date they stopped working in a job covered by the asbestos regulations. However, exposure may have been intermittent, and there was no indication of the intensity of exposure or of the type of asbestos involved. The job categories provide some information on the intensity and type of asbestos a worker was exposed to, but they take no account of differences between individual tasks within the job categories. The PMRs for lung cancer, asbestosis and mesothelioma by job category provide some insight into exposures overall; the relative sizes of PMRs are likely to reflect differing responses to exposure for each disease and different patterns of exposure within industry sectors. Manufacturing workers had lower asbestos-related disease risks than other sectors but a higher risk of IHD; this could be a reflection of lower intensity but longer duration exposures in this sector. Conversely, removal workers had among the highest PMRs for lung cancer, asbestosis and mesothelioma but the lowest risk of IHD. The asbestos removal industry is a relatively recent development and removal workers tended to be younger on entry into the study than workers in the other sectors; these two factors may in part account for their lower risk of cardiovascular disease mortality. Changes in the regulation of asbestos during the follow-up period completely altered the nature of the asbestos industry: use of amphibole asbestos was virtually eliminated by 1980 and by 1990, the insulation and manufacturing sectors no longer existed and asbestos removal work dominated the industry. Despite limitations in the variables representing asbestos exposure, statistically significant associations between these variables and mortality levels were observed in this study.

A major strength of the study was the availability of data on cigarette smoking, an important inflammatory agent and a risk factor for both diseases considered. This allowed confounding by 
smoking status to be controlled for in the analyses. The analysis showed that the increase in risk of IHD with age and with duration of exposure to asbestos was greater among neversmokers than among current smokers. Never smoking tends to be clustered with other healthy lifestyle choices, ${ }^{27} 28$ many of which are associated with a reduced risk of IHD. The finding that never-smokers' risk of IHD increased more rapidly with increasing duration of exposure than that of current smokers may provide some evidence of an association between asbestos exposure and IHD mortality, possibly through an inflammatory pathway, independent of any effects of cigarette smoking.

\section{CONCLUSION}

The findings from this study provide some evidence of an association between occupational exposure to asbestos and cardiovascular disease mortality in these workers.

Contributors $\mathrm{A}-\mathrm{HH}$ undertook the data analysis; $\mathrm{A}-\mathrm{HH}, \mathrm{AD}$ and JO jointly drafted the manuscript.

Funding This publication and the work it describes were funded by the Health and Safety Executive (HSE). Its contents, including any opinions and/or conclusions expressed, are those of the authors alone and do not necessarily reflect HSE policy.

Competing interests None

Patient consent Obtained.

Ethics approval British Medical Association.

Provenance and peer review Not commissioned; externally peer reviewed.

\section{REFERENCES}

1. Libby P. Inflammation and cardiovascular disease mechanisms. Am J Clin Nutr 2006;83:456S-60S.

2. Brook RD, Rajagopalan S, Pope CA 3rd, et al. Particulate matter air pollution and cardiovascular disease: an update to the scientific statement from the American Heart Association. Circulation 2010;121:2331-78.

3. Hales S, Edwards R. Cardiovascular effects of exposure to air pollution. BMJ 2011:343:d5814

4. Sun $\mathbf{0}$, Wang $A$, Jin $X$, et al. Long-term air pollution exposure and acceleration of atherosclerosis and vascular inflammation in an animal model. JAMA 2005;294:3003-10.

5. Araujo JA, Barajas B, Kleinman M, et al. Ambient particulate pollutants in the ultrafine range promote early atherosclerosis and systemic oxidative stress. Circ Res 2008;102:589-96.

6. Delfino RJ, Sioutas C, Malik S. Potential role of ultrafine particles in associations between airborne particle mass and cardiovascular health. Environ Health Perspect 2005;113:934-46.

7. Fukagawa NK, Li M, Sabo-Attwood T, et al. Inhaled asbestos exacerbates atherosclerosis in apolipoprotein E-deficient mice via CD4+ T cells. Environ Health Perspect 2008;116:1218-25.
8. Janssen YM, Driscoll KE, Howard B, et al. Asbestos causes translocation of $p 65$ protein and increases NF-kappa B DNA binding activity in rat lung epithelial and pleural mesothelial cells. Am J Pathol 1997;151:389-401.

9. Haegens A, Barrett TF, Gell J, et al. Airway epithelial NF-kappaB activation modulates asbestos-induced inflammation and mucin production in vivo. J Immunol 2007:178:1800-8.

10. Dement JM, Harris RL Jr, Symons MJ, et al. Exposures and mortality among chrysotile asbestos workers. Part II: mortality. Am J Ind Med 1983:4:421-33.

11. NIOSH. Asbestos Exposure Among Asbestos Textile, Friction, and Packing Plant Workers. 2003. http://www.cdc.gov/niosh/pgms/worknotify/asbestos.html

12. Mamo C, Costa G. Mortality Experience in an Historical Cohort of Chrysotile Asbestos Textile Workers. Global Asbestos Congress 2004. Tokyo, Japan: Epidemiology and Public Health Workshop, 2004.

13. Hein MJ, Stayner L, Lehman E, et al. Follow-up study of chrysotile textile workers: cohort mortality and exposure-response. Occup Environ Med 2007;64:616-25.

14. Sanden A, Jarvholm B, Larsson S. The importance of lung function, non-malignant diseases associated with asbestos, and symptoms as predictors of ischaemic heart disease in shipyard workers exposed to asbestos. Br J Ind Med 1993;50:785-90.

15. Harding $\mathbf{A H}$, Darnton A, Wegerdt J, et al. Mortality among British asbestos workers undergoing regular medical examinations (1971-2005). Occup Environ Med 2009:66:487-95.

16. Frost G, Harding AH, Darnton A, et al. Occupational exposure to asbestos and mortality among asbestos removal workers: a poisson regression analysis. $\mathrm{Br} \mathrm{J}$ Cancer 2008;99:822-9.

17. Sjögren B. Mortality among British asbestos workers. Occup Environ Med 2009;66:854-5.

18. Rockhill B, Newman B, Weinberg C. Use and misuse of population attributable fractions. Am J Public Health 1998:88:15-19.

19. Doll R, Peto R, Wheatley K, et al. Mortality in relation to smoking: 40 years' observations on male British doctors. BMJ 1994:309:901-11.

20. Katanoda K, Marugame T, Saika K, et al. Population attributable fraction of mortality associated with tobacco smoking in Japan: a pooled analysis of three large-scale cohort studies. J Epidemiol 2008;18:251-64.

21. Walker A, O'Brien M, Traynor J, et al. Living in Britain: Results From The 2001 General Household Survey. London: Stationery Office, 2002:275.

22. Yu IT, Tse LA. Exploring the joint effects of silicosis and smoking on lung cancer risks. Int J Cancer 2007;120:133-9.

23. Ferrario MM, Veronesi $\mathrm{G}$, Chambless LE, et al. The contribution of major risk factors and job strain to occupational class differences in coronary heart disease incidence: the MONICA Brianza and PAMELA population-based cohorts. Occup Environ Med 2011;68:717-22

24. Daniels MJ, Dominici F, Samet JM, et al. Estimating particulate matter-mortality dose-response curves and threshold levels: an analysis of daily time-series for the 20 largest US cities. Am J Epidemiol 2000:152:397-406.

25. US Department of Health and Human Services. The Health Consequences of Smoking: Cardiovascular Disease. A Report of the Surgeon General. Rockville, MD: US Department of Health and Human Services, Office of the Surgeon General, 1983.

26. US Department of Health and Human Services. How Tobacco Smoke Causes Disease: The Biology and Behavioral Basis for Smoking-Attributable Disease: A Report of the Surgeon General. Rockville, MD: U.S. Department of Health and Human Services, Office of the Surgeon General, 2010.

27. Schuit AJ, van Loon AJ, Tijhuis $M$, et al. Clustering of lifestyle risk factors in a general adult population. Prev Med 2002;35:219-24.

28. Poortinga W. The prevalence and clustering of four major lifestyle risk factors in an English adult population. Prev Med 2007:44:124-8. 